\title{
Matrix metalloproteinases in bone development and pathology: current knowledge and potential clinical utility
}

This article was published in the following Dove Press journal:

Metalloproteinases In Medicine

12 December 2016

Number of times this article has been viewed

\author{
Hai Po Helena Liang* \\ Joshua $\mathrm{Xu}^{*}$ \\ Meilang Xue \\ Christopher J Jackson
}

Sutton Arthritis Research Laboratory, Institute of Bone and Joint Research, Kolling Institute, Sydney Medical School Northern, University of Sydney, St Leonards, NSW, Australia

*These authors contributed equally to this work
Correspondence: Christopher J Jackson Sutton Arthritis Research Laboratory, Level I0, Kolling Institute, Royal North Shore Hospital, St Leonards, NSW 2065, Australia

Tel +6I $2992648 I 4$

Fax +6I 299266269

Email chris.jackson@sydney.edu.au

\begin{abstract}
Matrix metalloproteinases (MMPs) are degrading enzymes that have a pivotal function in extracellular matrix remodeling. More than half of the MMP members are expressed by bone and cartilage cells under physiological or pathological conditions such as rheumatoid arthritis, osteoarthritis, and osteoporosis. Through studies on the various bone diseases and on genetically modified mouse models in which one or more of the MMPs or their associated proteins and downstream signaling molecules have been targeted, it is becoming increasingly evident that MMPs and other players in their cellular pathway play a pivotal role in bone development and remodeling. This review details the latest findings related to MMPs and bone development and pathology.

Keywords: bone diseases, mouse models, gelatinases, collagenases, vascular endothelial growth factor, activated protein $\mathrm{C}$, bone morphogenetic proteins, transforming growth factor
\end{abstract}

\section{Introduction}

There are two vital processes during bone development that are responsible for bone formation, intramembranous ossification and endochondral ossification. Intramembranous ossification is a process that forms most of the craniofacial skeleton through the direct differentiation of mesenchymal cells into bone. ${ }^{1}$ In contrast, endochondral ossification is a process of bone development in which cartilage is used as a template for bone morphogenesis. ${ }^{1}$ Endochondral ossification is responsible for the development of most of the bones including the long bones. In this process, mesenchymal cells undergo condensation and then differentiate into chondrocytes, which proliferate and undergo hypertrophy before dying. ${ }^{1}$ This leaves cavities for the invasion of blood vessels and bone-forming/bone-remodeling cells such as osteoclasts, osteoblasts, and bone marrow. ${ }^{2}$ Following this, ossification gradually occurs along the cartilage template to replace it with bone. ${ }^{2}$ Successful bone growth requires a mechanically stable cartilage model that can be degraded during ossification to allow for mineral deposition and ultimately bone formation. ${ }^{2}$

The recruitment, survival, and function of osteoclasts and osteoblasts are essential for the prevention of metabolic bone diseases such as osteoporosis. In addition, these cells play an important role in promoting bone regeneration in pathological conditions such as rheumatoid arthritis (RA) and osteoarthritis (OA). RA and OA are characterized by synovitis, a destruction of the cartilage and the surrounding extracellular matrix (ECM). ${ }^{3}$ Remodeling of ECM in bones is therefore important for mediating bone development and repair. ${ }^{4,5}$ ECM remodeling in other areas including skin and blood 
vessels has also been indicated to mediate many different physiological and pathological processes, including wound healing and angiogenesis. ${ }^{6-9}$

Matrix metalloproteinases (MMPs) are a family of zincdependent ECM-degrading enzymes, which has been established to play a crucial role in ECM remodeling, ${ }^{10}$ and are the key enzymes responsible for cleaving structural components of the ECM such as collagen and gelatin, thereby enabling the ECM to degrade and regenerate. ${ }^{10}$ More than half of the MMP members are expressed in their active form by bone and cartilage cells under physiological and pathological conditions, and these MMPs are not only thought to have a pivotal involvement in bone and cartilage matrix degradation, but also important for osteoclast, osteoblast and osteocyte viability and functions, as well as chondrocyte proliferation and differentiation. ${ }^{8}$ This review provides an update on the role of MMPs in bone development and remodeling.

\section{Overview of the classification, structure, expression, and regulation of MMPs}

The 23 members of MMPs in humans (MMPs 1 through to 28, with MMP-4, MMP-5, MMP-6 and MMP-22 being removed from the classification due to duplication, and MMP-18 not found in humans) can be categorized into several different subtypes based on their structural and substrate affinity: collagenases (MMP-1, MMP-8 and MMP-13), gelatinases (MMP-2 and MMP-9), stromelysins (MMP-3, MMP-10 and MMP-11), matrilysins (MMP-7 and MMP26, membrane-type metalloproteinase (MMP-14, MMP-15, MMP-16, MMP-17 and MMP-24), and others (MMP-12, MMP-19, MMP-20, MMP-21, MMP-23, MMP-25, MMP-27 and MMP-28). Each member of these MMPs is encoded by a different gene, except for MMP-23, which is encoded by two identical genes (MMP-23A and MMP-23B) on chromosome $1 .{ }^{11}$ All MMPs share three common structures: the predomain (PRE) for protein secretion, the prodomain (PRO) responsible for the regulation of protein function, and the zinc-dependent catalytic endopeptidase motif, ${ }^{12}$ which are necessary for substrate processing. MMPs are expressed as inactive proenzymes that can be activated by the proteolytic cleavage of the propeptide to reveal its active site. The cleavage of the propeptide and activation of all MMPs, with the exception MMP-23, is thought to be mediated by a cysteine amino acid in the molecule's prodomain, via extracellular proteinases and other MMPs, in a process called "cysteine switching". ${ }^{13}$ The regulation of MMP expression and activity occurs at multiple levels, including gene transcription, ${ }^{14}$ translation and secretion of the inactive proenzyme, ${ }^{15}$ and proenzyme activation and inactivation via signaling from cytokines, growth factors, integrins, and ECM proteins. ${ }^{13,16}$ Examples of classic MMP activators include the activator protein-1, nuclear factor kappa B, tumor necrosis factor-alpha, transforming growth factor beta (TGF $\beta$ ), as well as certain interleukins. The main inhibitors of MMPs are the tissue inhibitors of MMPs (TIMPs) secreted by the ECM. ${ }^{17}$

\section{Roles of MMPs and TIMPs during bone development, remodeling, and repair}

Currently, the most abundantly expressed and functionally important MMPs in bone and cartilage cells during normal skeletal development are identified to be MMP-2 (also known as gelatinase A), MMP-9 (gelatinase B), MMP-13 (collagenase 3), MMP-14 (membrane-type $1 \mathrm{MMP}$ ), and MMP-16 (membrane-type 3), based on in vivo studies using MMP gene knockout mice and preclinical experimental arthritis models, as well as investigations of human genetic diseases involving MMP gene mutations. ${ }^{8}$ The roles of each of these MMPs and TIMPs are discussed as follows.

\section{MMP-2}

MMP-2, also known as gelatinase $\mathrm{A}$, is a $72 \mathrm{kDA}$ gelatinase that can cleave type I, IV, V, VII, and XI collagens along with aggrecans, gelatins, fibronectin, laminin, large tenascin-C, and elastin. ${ }^{18}$ Inactivating mutations of the human gene expressing MMP-2 were first identified in patients with inherited multicentric osteolysis and arthritis or the "vanishing bone" syndrome. This autosomal recessive condition was first reported in large Saudi Arabian families in which interfamilial marriage had occurred. ${ }^{19,20}$ The patients suffered from severe arthropathy, osteoporosis, and subcutaneous nodules with distinctive craniofacial defects that included exophthalmos, brachycephaly, and flattened nasal bridges. ${ }^{21}$ Children with multicentric osteolysis and arthritis exhibit normal birth weight but stunted growth rates in terms of both height and weight. ${ }^{21}$ By examining the population suffering from these distinctive bone phenotypes, the disease gene was identified at 16q12-21, a region encoding the expression of MMP-2. ${ }^{22}$

MMP-2 knockout mice have been used to elucidate the function of MMP-2 on bone. MMP-2 knockout mice, when compared to wild-type mice, were initially shown to have almost completely normal early development, with only a slight delay in bone development and were smaller in size at birth. ${ }^{23}$ However, further studies found that the long bones of MMP-2 knockout mice had osteopenia with the tibiae of many of these mice spontaneously becoming fractured. ${ }^{24}$ It is 
postulated that the reduced bone integrity in MMP-2 knockout mice is caused by disruptions to the osteocytic canalicular networks in bone. ${ }^{24}$ The canalicular spaces are locations in which mineral ion exchanges occur during the resorption and mineralization of the bone matrix..$^{25}$ Thus, disruption to these canalicular networks could possibly inhibit the mineralization and hardening of bone. An increase in MMP-2 protein expression has also been detected in fracture callus, and bone mineralization may be one aspect by which MMP-2 mediates bone remodeling during fracture repair. ${ }^{26}$ Nyman et al support this postulation as they found that the ratio of mineral to collagen is decreased in the bone of MMP-2 knockout mice. ${ }^{27}$ Along with the reduced bone mineralization density, the diaphysis cortex in the tibia of MMP-2 knockout mice is $23 \%$ thinner than the wild type. ${ }^{27}$ MMP-2 deficiency has also been shown to reduce tibia and femur length in adult mice. ${ }^{28}$ Histological analysis also revealed less dense and very disordered trabeculae. ${ }^{21}$ Since the osteocytic canalicular networks of MMP-2 knockout mice are repaired following transplantation of wild-type periosteum, MMP-2 may mediate its effects on bone via a local mechanism. ${ }^{24}$ Thus, MMP-2 appears to play a role in maintaining bone mineral density and strength, possibly via its local action on the ECM to produce canalicular networks.

The craniofacial defects observed in MMP-2 knockout mice are also comparable to those seen in humans with multicentric osteolysis and arthritis as a result of the inactivating mutation to the $M M P-2$ gene. The knockout mice have shorter, broader snouts along with hypertelorism and smaller jaws. ${ }^{21}$ It has been postulated that MMP-2 acts via type I collagen, as its inhibition of type I collagen cleavage caused similar craniofacial defects in mice as MMP-2 knockout. ${ }^{29}$ There is also abnormal bone development of the calvaria, which is the only bone reported to undergo sclerosis with increased bone deposition and osteocyte loss which is likely due to the increased osteoblastic activity in the calvarie. ${ }^{24}$ No changes in blastocyst activity have been detected in the long bones of MMP-2 knockout mice. ${ }^{24}$ These findings are interesting as ex vivo studies have shown poor proliferation of osteoblasts with MMP-2 knockout calvarial bone marrow stromal cells. ${ }^{21}$ In agreement, targeted siRNAmediated MMP-2 knockout decreases osteoblast proliferation ex vivo. ${ }^{21}$ The different findings in vivo and ex vivo can possibly be explained by the fact that MMP-2 knockout in mice can directly induce the expression of osteopontin and bone sialoprotein. ${ }^{30}$ While osteopontin has been shown to mediate an increase in osteoclast activity, bone sialoprotein can enhance osteoblast differentiation and activity. ${ }^{31,32}$ Thus, the varying expression of these two proteins in different bones can account for either increased bone reabsorption or bone growth. Ultimately, there is evidence that MMP-2 affects bone development via its effect on osteoclast and osteoblast activity and proliferation; however, the mechanisms are still not fully elucidated.

\section{MMP-9}

MMP-9, also known as gelatinase B, is a $92 \mathrm{kDa}$ collagenase that has high specific degradative activity for denatured collagens in the ECM. It can cleave elastin and native type IV, V, and XI collagens, but not non-native type I collagen, proteoglycan, or laminins. ${ }^{18,33}$ MMP-9 is also able to cleave non-ECM molecules such as substance $P$, amyloid beta peptide, and myelin basic protein. The expression of MMP-9 varies through the stages of development. In early development, MMP-9 is expressed in trophoblasts and osteoclasts, suggesting that it plays a role in implantation and bone resorption. ${ }^{34,35}$ With maturity, MMP-9 is primarily expressed in inflammatory cells during diseases such as RA and cancer. ${ }^{5}$

There are numerous postulated methods by which MMP-9 can influence bone development and strength. Long bones in MMP-9 knockout mice are 10\% shorter than those of the wild-type mice. ${ }^{33}$ These knockout mice also demonstrate an accumulation of lengthened hypertrophic chondrocytes at the growth plate, despite normal proliferation of these cells. ${ }^{33,36}$ It has been postulated that MMP-9 is required for the cleavage of galectin-3 to prevent accumulation of late hypertrophic chondrocytes. ${ }^{37}$ These findings suggest that MMP-9 plays a role in influencing the structural properties of whole bones through its activity at the growth plate during endochondral bone formation. This is supported by evidence that MMP-9 null mice have delayed skeletal growth plate vascularization and ossification of hypertrophic cartilage which is confined to just the growth plate cartilage. ${ }^{33}$ Bone marrow transplantation of MMP-9 null mice corrects all bone growth defects, suggesting that the critical cells expressing MMP-9 are of bone marrow origin. ${ }^{33}$ Interestingly, the MMP-9 null mice do not have any issues with implantation or development into fertile adults, suggesting that alternate physiological processes can compensate for some roles of MMP-9.

MMP-9 can also influence the bending strength and toughness of bone. MMP-9 knockout mice have improved connectivity density of the tibia trabeculae at the metaphysis with no overall volume changes. ${ }^{27}$ Yield strength, defined as the force required before plastic deformation, was slightly higher in the MMP-9 knockout mice when compared with the wild types. Interestingly, however, the bones of MMP-9 
knockout mice were more brittle. ${ }^{27}$ Although the mechanisms are not fully known, it is postulated that MMP-9 may affect ECM proteins such as type I collagen to alter ECM organization and thereby influence bone strength and brittleness. ${ }^{27,38}$ Recently, MMP-9 has been reported to also be necessary for the regulation of gene pathways that are required for osteoclastogenesis, through its proteolytic interaction with the histone H3 N-terminal tail (H3NT). ${ }^{39}$ Further studies must be conducted to better understand the mechanisms underlying these bone pathologies in MMP-9 null mice.

\section{MMP-I 3}

Cartilage consists of chondrocytes and a large amount of ECM, which is made up of proteoglycans, aggrecans, and collagens, mainly type II. Type II collagen is extremely resistant to degradation by most proteinases because of its triple-helical structure. Only the classical collagenases including MMP-1, MMP-8, and MMP-13, and to a much less extent, MMP-14, are able to degrade type II collagen fibrils and denature them into gelatin, which can then be subsequently digested into small peptides by the gelatinases. ${ }^{40}$ Due to its preferential digestion of type II collagen over other collagen types, MMP-13, which is derived from chondrocytes, synovial cells, and osteoblasts, is considered to be the most important collagenase for the degradation of cartilage. ${ }^{3,41}$

The proenzyme form of MMP-13 is $\sim 60 \mathrm{kDa}$ in size and can be activated by MMP-2, MMP-3, MMP-14, and plasmin. ${ }^{42}$ The expression and type II collagen degradation activity of the $48 \mathrm{kDa}$ active MMP-13 can also be upregulated by ECM proteins such as type $\mathrm{X}$ collagen $^{43}$ and periostin. ${ }^{44}$ There is now mounting evidence to suggest that increased MMP-13 activity is associated with articular cartilage degeneration and joint pathology typical of OA in animal models, and that MMP-13 expression is critical for OA disease progression. ${ }^{43-45}$ Therefore, the development of pharmacologic inhibitors of MMP-13 in recent years seems to be an effective strategy to modify OA disease outcome. ${ }^{46,47}$ In addition, a MMP-13 activity probe seems to be useful for in vivo imaging in $\mathrm{OA}$ disease diagnosis and differentiating disease severity. ${ }^{48,49}$ MMP-13-deficient mice also show significantly decreased disease severity in the antibody-induced arthritis model, thus implicating the important role of MMP-13 as a regulator of inflammation and revealing it as a potential therapeutic target for inflammatory arthritis. ${ }^{50}$

MMP-13 knockout mice exhibit a normal lifespan and are fertile, with no gross phenotypic abnormalities. However, these mice have demonstrated marked defects in their growth plate cartilage, with a significant increase in the hypertrophic chondrocyte zones but normal chondrocyte proliferation, and a delay in endochondral ossification, particularly at the secondary ossification center. The mice also show increased trabecular bone mass but irregular bone spicules. This subsequently results in impairment of bone matrix organization and cartilage ECM remodeling in these animals, which leads to a reduction in both toughness and fracture resistance of their long bones, but ultimately the mice show no notable abnormalities in their long bone development. ${ }^{51-53}$

MMP-13 is a downstream target of the transcription factor Cbfa1/Runx2 in hypertrophic chondrocytes, as Cbfa1 knockout mice fail to express MMP-13 during fetal development. ${ }^{54,55} \mathrm{C}$-maf deficiency, on the other hand, markedly suppresses collagen degradation by MMP-13, thereby resulting in abnormal terminal differentiation of chondrocytes which leads to prolongation of the chondrocyte hypertrophic state. ${ }^{56}$ Hence, MMP-13 has been implicated in the initiation of bone resorption.

MMP-9 and MMP-13 double knockout mice have exacerbated phenotypes compared to MMP-9 or MMP-13 single-knockout mice, including disorganized architecture of the hypertrophic chondrocyte zone and increased number of terminally differentiated hypertrophic chondrocytes. In contrast to MMP-13 single-knockout mice but similar to MMP-9 single-knockout mice, the double knockouts show a reduction of trabecular bone formation at the growth plate. Interestingly, there is no abnormality in aggrecan degradation in the MMP-9 and MMP-13 double knockouts, despite the absence of the aggrecan cleavage product in these mice, suggesting that other mechanisms exist for the removal of aggrecan during cartilage to bone transitions. ${ }^{33}$ This is consistent with a subsequent study on an aggrecan knock-in mouse strain that is resistant to cleavage by all MMPs in the aggrecan proteinase-sensitive interglobular domain. ${ }^{57}$

In humans, missense mutations in MMP-13 cause a genetic bone disorder called spondyloepimetaphyseal dysplasia characterized by defective growth and abnormal modeling of the spine and long bones in childhood, which spontaneously resolves by adolescence. These transient disease phenotypes appear to be caused by the late exit of chondrocytes from the growth plate, despite normal differentiation, consistent with the findings from knockout mice models. ${ }^{58}$ Further studies on the role of MMP-13 in bone remodeling in experimental arthritis mice models will likely provide better insights into the pathological process of such human bone disorders. 


\section{MMP-I4}

MMP-14 is a membrane-bound protein that is expressed highly by periskeletal and skeletal tissue. $.^{59,60} \mathrm{MMP}-14$ knockout mice have a very high mortality, with $33 \%$ of these dying due to wasting before they are weaned, and at 50-90 days nearly all these mutant mice die due to wasting. ${ }^{12}$ MMP-14 knockout mice also display abnormal cranial bone formation, short snouts, hypertelorism, and dome-shaped skulls along with growth impairment with respect to both weight and body size. ${ }^{12}$ MMP-2 and MMP-14 double knockout mice also die immediately after birth, ${ }^{61}$ and there may be some functional overlap between these two MMPs, as the cranial defects in MMP-14 deficiency are very similar to those seen in MMP2-deficient mice. ${ }^{12,24}$ It has been postulated that the MMP-14 knockout mouse inhibits fibroblast growth factor signaling, which is believed to be essential in intramembranous ossification of cranial bones. ${ }^{62}$ In addition, MMP-14 null mice show decreased MMP-2 activity, as expected since MMP-14 is the major activator of MMP-2. ${ }^{63,64}$

The bone mass of MMP-14 knockout mice is greatly reduced, with joints displaying articular cartilage loss. ${ }^{12}$ This is due to the greater bone resorption and reduced bone formation in MMP-14 knockout mice. ${ }^{65,66}$ MMP-14 knockout mice elicit these effects via intrinsic deficits to the osteogenic cells as opposed to other systemic causes. By culture-expanding populations of marrow-derived osteogenic cells from MMP-14 mice, it was found that these cells in particular display impaired osteogenic capacity and collagen-degrading activity. ${ }^{12}$ This may be mediated by the reduced ability for MMP-14 knockout animals to release CD44 from the cell membrane, ${ }^{67}$ as CD44 is important in osteocyte cell-cell signaling with its knockout producing shortened long bones and reduced osteoclast activity. ${ }^{67,68}$ MMP-14 may also interact with transduction signaling cascades, with a novel function of MMP-14 being its mechnosensory role in osteocytes. ${ }^{69,70}$

While the calcification of metaphyseal growth plates at birth is normal in MMP-14-deficient mice, there are significant delays in secondary epiphyseal ossification. ${ }^{12,65}$ In addition, vascularization of the epiphyseal growth cartilage does not occur, which is a finding comparable to that of MMP-9 knockout mice. ${ }^{33}$ Reconstituted MMP-14 activity has been shown to act on type II collagen-expressing cells to ameliorate skeletal dysplasia and rescue chondrocyte proliferation. ${ }^{71}$ Overall, it is believed that MMP-14 deficiency compromises apoptosis of chondrocytes and cartilage breakdown, preventing normal endochondral ossification. ${ }^{72}$ Thus, MMP-14 plays an important role in bone development and growth.

\section{MMP-I6}

MMP-16 present in osteoblasts and osteocytes ${ }^{41}$ acts by breaking down ECM proteins such as high-density fibrillar type I collagen, thus promoting bone growth and development. ${ }^{73}$ The mechanism of ECM degradation via MMP-16 is necessary for the proper functioning of mesenchymal cells expressed on skeletal tissue. ${ }^{73,74}$ In fact, mice lacking MMP-16 demonstrate stunted growth due to the decreased viability of these mesenchymal cells. ${ }^{73}$ MMP-16 has been examined along with MMP-14, as both enzymes have similar molecular structures and tissue expression patterns. ${ }^{73,75}$ In the double knockout of MMP-14 and MMP-16, the mortality was even higher than that of MMP-14 alone as described earlier, with the majority dying within the first day of birth due to developmental abnormalities. In contrast, the single knockout of MMP-16 did not result in any premature deaths. ${ }^{73}$ This suggests that MMP-16 is not essential for post-embryonic bone development in mice, unlike MMP-14. Furthermore, the double knockout of MMP-14 and MMP-16 led to even more pronounced craniofacial deformities and cortical bone shortening than that observed in the single deficiencies. ${ }^{73}$ The loss of both the MMPs also elicited greater nuclei apoptosis in the bone-lining cells along with reduced chondrocyte proliferation and cartilage remodeling, when compared to single knockout of the $M M P-14$ gene. These observations not only are tied to the loss of bone collagenolytic activity, but also imply that MMP-16 can partly compensate for the action of MMP-14. ${ }^{73}$

\section{TIMPs}

TIMP-1 and TIMP-2 are the most studied natural inhibitors of the MMPs and the most highly expressed during bone development. TIMP-1 is expressed in chondrocytes of all zones in the growth plate, as well as in osteoblasts, osteocytes, and osteoclasts. ${ }^{41,76}$ Mice overexpressing TIMP-1 in osteoblasts were found by Geoffroy et $\mathrm{al}^{77}$ to have increased trabecular bone volume and decreased bone turnover, hence indicative of an important regulatory role in bone formation and remodeling that is likely to be dependent on its MMP inhibitory activity. TIMP-2 has also been found to be expressed by hypertrophic chondrocytes and osteoblasts, ${ }^{41}$ and both TIMP-1 and TIMP-2 are able to directly stimulate the bone-resorbing activity of osteoclasts in vitro at physiological concentrations, and this is likely to be independent of their inhibition of MMPs. ${ }^{78}$ Other TIMP members including TIMP-3 and TIMP-4 are also expressed in bone and joint tissues, and an increased expression of these have been associated with OA..$^{79,80}$ TIMP-3 knockout mice were found 
to have mild cartilage degradation similar to that observed in osteoarthritic patients, as a result of increased type II collagen degradation. ${ }^{81}$ On the other hand, overexpression of TIMP-3 in hematopoietic cells was shown to result in fatal osteosclerosis in mice. ${ }^{82}$ Most recently, the gene expressions of TIMP-1, TIMP-2, and TIMP-3 were all found to be increased in the process of osteocytic differentiation during bone matrix mineralization. ${ }^{83}$

\section{Interactions of MMPs with other proteins in bone development, remodeling, and repair}

Other proteins that interact with the aforementioned MMPs in bone development and disease are briefly described as follows and are summarized in Table 1.

\section{TGF $\beta$}

The actions of MMPs on bone turnover and remodeling can be exerted via its interaction with various other proteins. Both MMP-2 and MMP-9 can regulate the bioavailability and bioactivity of TGF $\beta$, a molecule that affects the mechanical properties and composition of bone matrix. ${ }^{27,84,85}$ When TGF $\beta$ signaling is increased in mice, the modulus and hardness of their bones decrease. ${ }^{85}$ In addition, MMP-14 expressed by osteoblasts has also been reported to have the ability to activate TGF $\beta$, thereby maintaining the survival of osteoblasts upon completion of bone matrix synthesis during bone remodeling and driving them to differentiate into osteocytes. ${ }^{86}$ Conversely, TGF $\beta$ is able to significantly upregulate MMP13 expression in osteoblasts, thereby inducing changes in osteoblast morphology that in turn promotes osteoclastic bone resorption. ${ }^{87}$

\section{Bone morphogenetic proteins}

Bone morphogenetic proteins (BMPs) are multifunctional secreted growth factors that also belong to the TGF $\beta$ superfamily. ${ }^{88}$ Conditional and tissue-specific knockout mouse models provide strong evidence on the pivotal roles of BMPs, as well as their receptors and effectors, in bone formation and resorption. ${ }^{88-90}$ Inhibition of the BMP receptor and its downstream signaling by a pharmacological ligand significantly reduces the expression and activity of both MMP-2 and MMP-9, thereby obstructing tissue regeneration and remodeling in teleost fish Poecilia latipinna following amputation. ${ }^{91}$ Similarly in mice with BMP type IA receptor (BMPRIA) deficiency specifically in osteoblasts, MMP-9 expressed by osteoclasts was significantly reduced, impairing bone resorption and finally resulting in increased bone mass during early development. ${ }^{90}$ Additionally, Choi et al ${ }^{92}$ reported that downregulation of MMP-9 activity promotes

Table I Proteins that interact with MMPs and TIMPs in bone development and disease

\begin{tabular}{|c|c|c|}
\hline Protein & Interacting MMPs & Effects \\
\hline \multirow[t]{4}{*}{ TGF $\beta$} & MMP-2 & $\begin{array}{l}\text { MMP-2 regulates the bioavailability and bioactivity of TGF } \beta \text {, thereby affecting bone hardness and bone matrix } \\
\text { composition }^{27,84,85}\end{array}$ \\
\hline & MMP-9 & $\begin{array}{l}\text { MMP-9 regulates the bioavailability and bioactivity of TGF } \beta \text {, thereby affecting bone hardness and bone matrix } \\
\text { composition }{ }^{27,84,85}\end{array}$ \\
\hline & MMP-I3 & $\begin{array}{l}\text { MMP- } 13 \text { is upregulated by TGF } \beta \text {, which induces changes in osteoblast morphology and promotes bone } \\
\text { resorption }{ }^{87}\end{array}$ \\
\hline & MMP-I4 & MMP-I4 activates TGF $\beta$, which helps to regulate osteoblast differentiation and survival ${ }^{86}$ \\
\hline \multirow[t]{2}{*}{ BMP } & MMP-2 & MMP- 2 is regulated by BMP, thereby affecting tissue regeneration and remodeling ${ }^{91}$ \\
\hline & MMP-9 & $\begin{array}{l}\text { MMP-9 is regulated by BMP, thereby affecting bone resorption and remodeling, as well as chondrocyte } \\
\text { commitment }{ }^{90-92}\end{array}$ \\
\hline \multirow[t]{3}{*}{ Wnt/ß-catenin } & MMP-2 & $\begin{array}{l}\text { MMP-2 is regulated by } \mathrm{Wnt} / \beta \text {-catenin signaling, thereby modulating chondrocyte function and affecting } \\
\text { growth plate organization, cartilage formation, and endochondral ossification during bone development }{ }^{105}\end{array}$ \\
\hline & MMP-9 & $\begin{array}{l}\text { MMP-9 is upregulated by } \mathrm{Wnt} / \beta \text {-catenin signaling, thereby modulating bone resorption and cartilage } \\
\text { degradation } \\
90,100,105\end{array}$ \\
\hline & MMP-I3 & $\begin{array}{l}\text { MMP- } 13 \text { is regulated by } \mathrm{Wnt} / \beta \text {-catenin signaling, thereby modulating vascularization of cartilage during } \\
\text { development, bone formation, and remodeling }{ }^{102-105}\end{array}$ \\
\hline VEGF & MMP-9 & $\begin{array}{l}\text { MMP-9 regulates the bioavailability and bioactivity of VEGF, thereby affecting osteoclast recruitment during } \\
\text { bone resorption }\end{array}$ \\
\hline \multirow[t]{2}{*}{ aPC } & MMP-2 & $\begin{array}{l}\text { MMP- } 2 \text { activity is upregulated by aPC in RA patients, thereby suppressing pro-inflammatory signaling as well } \\
\text { as bone and cartilage degradation in RA patients. }{ }^{116-118}\end{array}$ \\
\hline & MMP-9 & $\begin{array}{l}\text { MMP-9 activity is downregulated by aPC in synovial fibroblasts, thereby suppressing pro-inflammatory } \\
\text { signaling as well as bone and cartilage degradation in RA patients }{ }^{117,119}\end{array}$ \\
\hline TIMPs & All MMPs & MMP inhibitors that can regulate osteocytic differentiation, bone formation, resorption, and remodeling ${ }^{41,76-83}$ \\
\hline
\end{tabular}

Abbreviations: aPC, activated protein C; BMP, bone morphogenetic protein; MMP, matrix metalloproteinase; RA, rheumatoid arthritis; TGF $\beta$; transforming growth factor beta; TIMP, tissue inhibitor of MMPs; VEGF, vascular endothelial growth factor. 
BMP-2-induced chondrocyte commitment of the mouse C3H10T1/2 stem cell line via modulation of glycogen synthase kinase- $3 \beta$ signaling.

\section{Wnt/beta-catenin}

Wnt proteins are a large glycoprotein family that play important roles in various development and cell renewal processes, ${ }^{93,94}$ and there is increasing evidence that suggests that the canonical Wnt/ $\beta$-catenin signaling pathway may be involved in cartilage destruction in RA and OA. ${ }^{94-96}$ Various research groups have reported that the expressions of several Wnt proteins, as well as the expressions of Wnt inhibitors known as the frizzled-related proteins, were altered in the synovium and cartilage of RA and OA patients compared to normal controls. ${ }^{97-99}$ BMP-induced $\mathrm{Wnt} / \beta$-catenin signaling was demonstrated to regulate the expressions of TGF $\beta$, MMP-2, MMP-9, MMP-13, and TIMP-1 in various bone cells including osteoblasts, osteoclasts, and articular chondrocytes, ${ }^{90,100-105}$ which can ultimately regulate bone and cartilage formation, development, and remodeling, and hence have important implications in bone disease progression.

\section{Vascular endothelial growth factor}

Vascular endothelial growth factor (VEGF), an important angiogenic factor that acts mainly on endothelial cells, but also stimulates osteoblasts and OA chondrocytes, ${ }^{106,107}$ has been implicated to regulate endochondral ossification and bone formation. ${ }^{108}$ The bioavailability and activity of VEGF is believed to be at least partially regulated by MMP-9. ${ }^{108,109}$ In addition, MMP-9 has been suggested to specifically regulate the ECM-bound VEGF, exerting direct chemotactic activity on osteoclasts, thereby affecting their recruitment during bone resorption. ${ }^{110}$

\section{Activated protein $\mathrm{C}$}

Activated protein $\mathrm{C}$ (aPC) is best known for its anticoagulant activity. However, it also has potent ability to promote growth and dampen inflammation. ${ }^{11-114}$ aPC increases osteoblast viability and signaling, promotes recombinant human recombinant BMP-2-induced ectopic bone formation, and enhances angiogenesis in vivo in a protease-activated receptor-1-dependent manner, ${ }^{115}$ suggesting that aPC may have the potential to be used in conjunction with rhBMP-2 as a therapeutic for bone repair. ${ }^{115}$ APC was first reported to play a role in regulating MMP activity by Nguyen et al ${ }^{116}$ who showed that aPC directly activates MMP-2 in human umbilical vein endothelial cells. In RA, aPC co-localizes with and selectively upregulates and activates MMP-2, while at the same time inhibiting MMP-9 in synovial fibroblasts and monocytes, resulting in suppressing of the pro-inflammatory signaling in RA patients. ${ }^{17,118}$ This is explained by the finding that endogenous MMP-9 but not MMP-2 promotes rheumatoid synovial fibroblast survival, inflammation, and cartilage degradation resulting in potential bone loss. ${ }^{119}$

\section{Conclusion}

In summary, bone is a highly dynamic and continuously remodeling tissue during development, homeostasis, and tissue repair. Half of the MMP members have been detected in bone tissue during development and in pathological conditions involving bone degradation. Knockout mouse models have confirmed the crucial functions of MMPs during bone development and regeneration. MMPs and proteins that modulate or are modulated by MMPs are potential targets for improving bone tissue repair. Better understanding of the regulatory mechanisms of MMPs and further elucidation of their cellular pathways in ECM remodeling is necessary for future therapeutic development.

\section{Disclosure}

The authors report no conflicts of interest in this work.

\section{References}

1. Ortega N, Behonick DJ, Werb Z. Matrix remodeling during endochondral ossification. Trends Cell Biol. 2004;14(2):86-93.

2. Mackie EJ, AhmedYA, Tatarczuch L, Chen KS, Mirams M. Endochondral ossification: how cartilage is converted into bone in the developing skeleton. Int J Biochem Cell Biol. 2008;40(1):46-62.

3. Takaishi H, Kimura T, Dalal S, Okada Y, D'Armiento J. Joint diseases and matrix metalloproteinases: a role for MMP-13. Curr Pharm Biotechnol. 2008;9(1):47-54.

4. Behonick DJ, Xing Z, Lieu S, et al. Role of matrix metalloproteinase 13 in both endochondral and intramembranous ossification during skeletal regeneration. PloS One. 2007;2(11):e1150.

5. Vu TH, Werb Z. Matrix metalloproteinases: effectors of development and normal physiology. Genes Dev. 2000;14(17):2123-2133.

6. Hua H, Li M, Luo T, Yin Y, Jiang Y. Matrix metalloproteinases in tumorigenesis: an evolving paradigm. Cell Mol Life Sci. 2011;68(23): 3853-3868.

7. Deryugina EI, Quigley JP. Tumor angiogenesis: MMP-mediated induction of intravasation- and metastasis-sustaining neovasculature. Matrix Biol. 2015;44-46:94-112.

8. Paiva KB, Granjeiro JM. Bone tissue remodeling and development: focus on matrix metalloproteinase functions. Arch Biochem Biophys. 2014;561:74-87.

9. Xue M, Le NT, Jackson CJ. Targeting matrix metalloproteases to improve cutaneous wound healing. Expert Opin Ther Targets. 2006; 10(1):143-155.

10. Le NT, Xue M, Castelnoble LA, Jackson CJ. The dual personalities of matrix metalloproteinases in inflammation. Front Biosci. 2007; 12:1475-1487.

11. Nagase H, Visse R, Murphy G. Structure and function of matrix metalloproteinases and TIMPs. Cardiovasc Res. 2006;69(3):562-573.

12. Holmbeck K, Bianco P, Caterina J, et al. MT1-MMP-deficient mice develop dwarfism, osteopenia, arthritis, and connective tissue disease due to inadequate collagen turnover. Cell. 1999;99(1):81-92.

13. Ra HJ, Parks WC. Control of matrix metalloproteinase catalytic activity. Matrix Biol. 2007;26(8):587-596. 
14. Yan C, Boyd DD. Regulation of matrix metalloproteinase gene expression. J Cell Physiol. 2007;211(1):19-26.

15. Clark IM, Swingler TE, Sampieri CL, Edwards DR. The regulation of matrix metalloproteinases and their inhibitors. Int J Biochem Cell Biol. 2008;40(6-7):1362-1378.

16. Stamenkovic I. Extracellular matrix remodelling: the role of matrix metalloproteinases. J Pathol. 2003;200(4):448-464.

17. Hadler-Olsen E, Fadnes B, Sylte I, Uhlin-Hansen L, Winberg JO. Regulation of matrix metalloproteinase activity in health and disease. FEBS J. 2011;278(1):28-45.

18. Shimokawa Ki K, Katayama M, Matsuda Y, et al. Matrix metalloproteinase (MMP)-2 and MMP-9 activities in human seminal plasma. Mol Hum Reprod. 2002;8(1):32-36.

19. Al Aqeel A, Al Sewairi W, Edress B, Gorlin RJ, Desnick RJ, Martignetti JA. Inherited multicentric osteolysis with arthritis: a variant resembling Torg syndrome in a Saudi family. Am J Med Genet. 2000;93(1):11-18.

20. Al-Mayouf SM, Majeed M, Hugosson C, Bahabri S. New form of idiopathic osteolysis: nodulosis, arthropathy and osteolysis (NAO) syndrome. Am J Med Genet. 2000;93(1):5-10.

21. Mosig RA, Dowling O, DiFeo A, et al. Loss of MMP-2 disrupts skeletal and craniofacial development and results in decreased bone mineralization, joint erosion and defects in osteoblast and osteoclast growth. Hum Mol Genet. 2007;16(9):1113-1123.

22. Martignetti JA, Aqeel AA, Sewairi WA, et al. Mutation of the matrix metalloproteinase 2 gene (MMP2) causes a multicentric osteolysis and arthritis syndrome. Nat Genet. 2001;28(3):261-265.

23. Itoh $\mathrm{T}$, Ikeda $\mathrm{T}$, Gomi $\mathrm{H}$, Nakao $\mathrm{S}$, Suzuki T, Itohara S. Unaltered secretion of beta-amyloid precursor protein in gelatinase A (matrix metalloproteinase 2)-deficient mice. J Biol Chem. 1997;272(36):22389-22392.

24. Inoue K, Mikuni-Takagaki Y, Oikawa K, et al. A crucial role for matrix metalloproteinase 2 in osteocytic canalicular formation and bone metabolism. J Biol Chem. 2006;281(44):33814-33824.

25. Marenzana M, Shipley AM, Squitiero P, Kunkel JG, Rubinacci A. Bone as an ion exchange organ: evidence for instantaneous cell-dependent calcium efflux from bone not due to resorption. Bone. 2005;37(4):545-554.

26. Lieu S, Hansen E, Dedini R, et al. Impaired remodeling phase of fracture repair in the absence of matrix metalloproteinase-2. Dis Model Mech. 2011;4(2):203-211.

27. Nyman JS, Lynch CC, Perrien DS, et al. Differential effects between the loss of MMP-2 and MMP-9 on structural and tissue-level properties of bone. J Bone Miner Res. 2011;26(6):1252-1260.

28. Madsen DH, Jurgensen HJ, Ingvarsen S, et al. Differential actions of the endocytic collagen receptor uPARAP/Endo180 and the collagenase MMP-2 in bone homeostasis. PloS One. 2013;8(8):e71261.

29. Egeblad M, Shen HC, Behonick DJ, et al. Type I collagen is a genetic modifier of matrix metalloproteinase 2 in murine skeletal development. Dev Dyn. 2007;236(6):1683-1693.

30. Mosig RA, Martignetti JA. Loss of MMP-2 in murine osteoblasts upregulates osteopontin and bone sialoprotein expression in a circuit regulating bone homeostasis. Dis Model Mech. 2013;6(2):397-403.

31. Gordon JA, Tye CE, Sampaio AV, Underhill TM, Hunter GK, Goldberg HA. Bone sialoprotein expression enhances osteoblast differentiation and matrix mineralization in vitro. Bone. 2007;41(3):462-473.

32. Shapses SA, Cifuentes M, Spevak L, et al. Osteopontin facilitates bone resorption, decreasing bone mineral crystallinity and content during calcium deficiency. Calcif Tissue Int. 2003;73(1):86-92.

33. Vu TH, Shipley JM, Bergers G, et al. MMP-9/gelatinase B is a key regulator of growth plate angiogenesis and apoptosis of hypertrophic chondrocytes. Cell. 1998;93(3):411-422.

34. Reponen P, Sahlberg C, Munaut C, Thesleff I, Tryggvason K. High expression of 92-kDa type IV collagenase (gelatinase) in the osteoclast lineage during mouse development. Ann N Y Acad Sci. 1994; 732:472-475.

35. Alexander CM, Hansell EJ, Behrendtsen O, et al. Expression and function of matrix metalloproteinases and their inhibitors at the maternal-embryonic boundary during mouse embryo implantation. Development. 1996;122(6):1723-1736.
36. Kojima T, Hasegawa T, de Freitas PH, et al. Histochemical aspects of the vascular invasion at the erosion zone of the epiphyseal cartilage in MMP-9-deficient mice. Biomed Res. 2013;34(3):119-128.

37. Ortega N, Behonick DJ, Colnot C, Cooper DN, Werb Z. Galectin-3 is a downstream regulator of matrix metalloproteinase-9 function during endochondral bone formation. Mol Biol Cell. 2005;16(6):3028-3039.

38. Nyman JS, Reyes M, Wang X. Effect of ultrastructural changes on the toughness of bone. Micron. 2005;36(7-8):566-582.

39. Kim K, Punj V, Kim JM, et al. MMP-9 facilitates selective proteolysis of the histone $\mathrm{H} 3$ tail at genes necessary for proficient osteoclastogenesis. Genes Dev. 2016;30(2):208-219.

40. Krane SM. Petulant cellular acts: destroying the ECM rather than creating it. J Clin Invest. 2001;107(1):31-32.

41. Haeusler G, Walter I, Helmreich M, Egerbacher M. Localization of matrix metalloproteinases, (MMPs) their tissue inhibitors, and vascular endothelial growth factor (VEGF) in growth plates of children and adolescents indicates a role for MMPs in human postnatal growth and skeletal maturation. Calcif Tissue Int. 2005;76(5):326-335.

42. Knauper V, Will H, Lopez-Otin C, et al. Cellular mechanisms for human procollagenase-3 (MMP-13) activation. Evidence that MT1MMP (MMP-14) and gelatinase a (MMP-2) are able to generate active enzyme. J Biol Chem. 1996;271(29):17124-17131.

43. Neuhold LA, Killar L, Zhao W, et al. Postnatal expression in hyaline cartilage of constitutively active human collagenase-3 (MMP-13) induces osteoarthritis in mice. J Clin Invest. 2001;107(1):35-44.

44. Attur M, Yang Q, Shimada K, et al. Elevated expression of periostin in human osteoarthritic cartilage and its potential role in matrix degradation via matrix metalloproteinase-13. FASEB J. 2015;29(10):4107-4121.

45. Wang M, Sampson ER, Jin H, et al. MMP13 is a critical target gene during the progression of osteoarthritis. Arthritis Res Ther: 2013;15(1):R5.

46. Hu W, Zhang W, Li F, Guo F, Chen A. Bortezomib prevents the expression of MMP-13 and the degradation of collagen type 2 in human chondrocytes. Biochem Biophys Res Commun. 2014;452(3):526-530.

47. Ruminski PG, Massa M, Strohbach J, et al. Discovery of N-(4-fluoro-3methoxybenzyl)-6-(2-(((2S,5R)-5-(hydroxymethyl)-1,4-dioxan-2-yl) met hyl)-2H-tetrazol-5-yl)-2-methylpyrimidine-4-carboxamide. A highly selective and orally bioavailable matrix metalloproteinase- 13 inhibitor for the potential treatment of osteoarthritis. J Med Chem. 2016; 59(1):313-327.

48. Lim NH, Meinjohanns E, Meldal M, Bou-Gharios G, Nagase H. In vivo imaging of MMP-13 activity in the murine destabilised medial meniscus surgical model of osteoarthritis. Osteoarthritis Cartilage. 2014; 22(6):862-868.

49. Lim NH, Meinjohanns E, Bou-Gharios G, et al. In vivo imaging of matrix metalloproteinase 12 and matrix metalloproteinase 13 activities in the mouse model of collagen-induced arthritis. Arthritis Rheumatol. 2014;66(3):589-598.

50. Singh A, Rajasekaran N, Hartenstein B, et al. Collagenase-3 (MMP-13) deficiency protects C57BL/6 mice from antibody-induced arthritis. Arthritis Res Ther. 2013;15(6):R222.

51. Inada M, Wang Y, Byrne MH, et al. Critical roles for collagenase-3 (Mmp13) in development of growth plate cartilage and in endochondral ossification. Proc Natl Acad Sci U S A. 2004;101(49):17192-17197.

52. Stickens D, Behonick DJ, Ortega N, et al. Altered endochondral bone development in matrix metalloproteinase 13-deficient mice. Development. 2004;131(23):5883-5895.

53. Tang SY, Herber RP, Ho SP, Alliston T. Matrix metalloproteinase-13 is required for osteocytic perilacunar remodeling and maintains bone fracture resistance. J Bone Miner Res. 2012;27(9):1936-1950.

54. Jimenez MJ, Balbin M, Lopez JM, Alvarez J, Komori T, Lopez-Otin C. Collagenase 3 is a target of $\mathrm{Cbfa} 1$, a transcription factor of the runt gene family involved in bone formation. Mol Cell Biol. 1999;19(6):4431-4442.

55. Jimenez MJ, Balbin M, Alvarez J, et al. A regulatory cascade involving retinoic acid, $\mathrm{Cbfa} 1$, and matrix metalloproteinases is coupled to the development of a process of perichondrial invasion and osteogenic differentiation during bone formation. J Cell Biol. 2001; 155(7):1333-1344. 
56. MacLean HE, Kim JI, Glimcher MJ, Wang J, Kronenberg HM, Glimcher LH. Absence of transcription factor c-maf causes abnormal terminal differentiation of hypertrophic chondrocytes during endochondral bone development. Dev Biol. 2003;262(1):51-63.

57. Little CB, Meeker CT, Hembry RM, et al. Matrix metalloproteinases are not essential for aggrecan turnover during normal skeletal growth and development. Mol Cell Biol. 2005;25(8):3388-3399.

58. Kennedy AM, Inada M, Krane SM, et al. MMP13 mutation causes spondyloepimetaphyseal dysplasia, Missouri type (SEMD(MO). $J$ Clin Invest. 2005;115(10):2832-2842.

59. Ohuchi E, Imai K, Fujii Y, Sato H, Seiki M, Okada Y. Membrane type 1 matrix metalloproteinase digests interstitial collagens and other extracellular matrix macromolecules. J Biol Chem. 1997; 272(4):2446-2451.

60. Kinoh H, Sato H, Tsunezuka Y, et al. MT-MMP, the cell surface activator of proMMP-2 (pro-gelatinase A), is expressed with its substrate in mouse tissue during embryogenesis. J Cell Sci. 1996;109(Pt 5): 953-959.

61. Oh J, Takahashi R, Adachi E, et al. Mutations in two matrix metalloproteinase genes, MMP-2 and MT1-MMP, are synthetic lethal in mice. Oncogene. 2004;23(29):5041-5048.

62. Hatch NE. FGF signaling in craniofacial biological control and pathological craniofacial development. Crit Rev Eukaryot Gene Expr. 2010;20(4):295-311.

63. Oblander SA, Zhou Z, Galvez BG, et al. Distinctive functions of membrane type 1 matrix-metalloprotease (MT1-MMP or MMP-14) in lung and submandibular gland development are independent of its role in pro-MMP-2 activation. Dev Biol. 2005;277(1):255-269.

64. Strongin AY, Collier I, Bannikov G, Marmer BL, Grant GA, Goldberg GI. Mechanism of cell surface activation of 72-kDa type IV collagenase. Isolation of the activated form of the membrane metalloprotease. J Biol Chem. 1995;270(10):5331-5338.

65. Zhao W, Byrne MH, Wang Y, Krane SM. Osteocyte and osteoblast apoptosis and excessive bone deposition accompany failure of collagenase cleavage of collagen. J Clin Invest. 2000;106(8):941-949.

66. Holmbeck K, Bianco P, Pidoux I, et al. The metalloproteinase MT1MMP is required for normal development and maintenance of osteocyte processes in bone. J Cell Sci. 2005;118(Pt 1):147-156.

67. Kajita M, Itoh Y, Chiba T, et al. Membrane-type 1 matrix metalloproteinase cleaves CD44 and promotes cell migration. J Cell Biol. 2001;153(5):893-904.

68. Hughes DE, Salter DM, Simpson R. CD44 expression in human bone: a novel marker of osteocytic differentiation. J Bone Miner Res. 1994;9(1):39-44.

69. Eisenach PA, Roghi C, Fogarasi M, Murphy G, English WR. MT1MMP regulates VEGF-A expression through a complex with VEGFR-2 and Src. J Cell Sci. 2010;123(Pt 23):4182-4193.

70. Kulkarni RN, Bakker AD, Gruber EV, et al. MT1-MMP modulates the mechanosensitivity of osteocytes. Biochem Biophys Res Commun. 2012;417(2):824-829.

71. Szabova L, Yamada SS, Wimer H, et al. MT1-MMP and type II collagen specify skeletal stem cells and their bone and cartilage progeny. J Bone Miner Res. 2009;24(11):1905-1916.

72. Holmbeck K, Bianco P, Chrysovergis K, Yamada S, Birkedal-Hansen H. MT1-MMP-dependent, apoptotic remodeling of unmineralized cartilage: a critical process in skeletal growth. $J$ Cell Biol. 2003; 163(3):661-671.

73. Shi J, Son MY, Yamada S, et al. Membrane-type MMPs enable extracellular matrix permissiveness and mesenchymal cell proliferation during embryogenesis. Dev Biol. 2008;313(1):196-209.

74. Loffek S, Schilling O, Franzke CW. Series "matrix metalloproteinases in lung health and disease": biological role of matrix metalloproteinases: a critical balance. Eur Respir J. 2011;38(1):191-208

75. Szabova L, Yamada SS, Birkedal-Hansen H, Holmbeck K. Expression pattern of four membrane-type matrix metalloproteinases in the normal and diseased mouse mammary gland. $J$ Cell Physiol. 2005;205(1):123-132.
76. Bord S, Horner A, Beeton CA, Hembry RM, Compston JE. Tissue inhibitor of matrix metalloproteinase-1 (TIMP-1) distribution in normal and pathological human bone. Bone. 1999;24(3):229-235.

77. Geoffroy V, Marty-Morieux C, Le Goupil N, et al. In vivo inhibition of osteoblastic metalloproteinases leads to increased trabecular bone mass. J Bone Miner Res. 2004;19(5):811-822.

78. Sobue T, Hakeda Y, Kobayashi Y, et al. Tissue inhibitor of metalloproteinases 1 and 2 directly stimulate the bone-resorbing activity of isolated mature osteoclasts. J Bone Miner Res. 2001;16(12): $2205-2214$.

79. Su S, Grover J, Roughley PJ, et al. Expression of the tissue inhibitor of metalloproteinases (TIMP) gene family in normal and osteoarthritic joints. Rheumatol Int. 1999;18(5-6):183-191.

80. Huang W, Li WQ, Dehnade F, Zafarullah M. Tissue inhibitor of metalloproteinases-4 (TIMP-4) gene expression is increased in human osteoarthritic femoral head cartilage. J Cell Biochem. 2002; 85(2):295-303.

81. Sahebjam S, Khokha R, Mort JS. Increased collagen and aggrecan degradation with age in the joints of Timp3(-/-) mice. Arthritis Rheum. 2007;56(3):905-909.

82. Shen Y, Winkler IG, Barbier V, Sims NA, Hendy J, Levesque JP. Tissue inhibitor of metalloproteinase-3 (TIMP-3) regulates hematopoiesis and bone formation in vivo. PloS One. 2010;5(9):e13086.

83. Prideaux M, Staines KA, Jones ER, Riley GP, Pitsillides AA, Farquharson C. MMP and TIMP temporal gene expression during osteocytogenesis. Gene Expr Patterns. 2015;18(1-2):29-36.

84. Dallas SL, Miyazono K, Skerry TM, Mundy GR, Bonewald LF. Dual role for the latent transforming growth factor-beta binding protein in storage of latent TGF-beta in the extracellular matrix and as a structural matrix protein. $J$ Cell Biol. 1995;131(2):539-549.

85. Balooch G, Balooch M, Nalla RK, et al. TGF-beta regulates the mechanical properties and composition of bone matrix. Proc Natl Acad Sci U S A. 2005;102(52):18813-18818.

86. Karsdal MA, Larsen L, Engsig MT, et al. Matrix metalloproteinasedependent activation of latent transforming growth factor-beta controls the conversion of osteoblasts into osteocytes by blocking osteoblast apoptosis. J Biol Chem. 2002;277(46):44061-44067.

87. Karsdal MA, Fjording MS, Foged NT, Delaisse JM, Lochter A. Transforming growth factor-beta-induced osteoblast elongation regulates osteoclastic bone resorption through a p 38 mitogen-activated protein kinase- and matrix metalloproteinase-dependent pathway. J Biol Chem. 2001;276(42):39350-39358.

88. Biver E, Hardouin P, Caverzasio J. The "bone morphogenic proteins" pathways in bone and joint diseases: translational perspectives from physiopathology to therapeutic targets. Cytokine Growth Factor Rev. 2013;24(1):69-81.

89. Kamiya N, Mishina Y. New insights on the roles of BMP signaling in bone - A review of recent mouse genetic studies. BioFactors. 2011; 37(2):75-82.

90. Kamiya N, Ye L, Kobayashi T, et al. BMP signaling negatively regulates bone mass through sclerostin by inhibiting the canonical Wnt pathway. Development. 2008;135(22):3801-3811.

91. Rajaram S, Murawala H, Buch P, Patel S, Balakrishnan S. Inhibition of BMP signaling reduces MMP-2 and MMP-9 expression and obstructs wound healing in regenerating fin of teleost fish Poecilia latipinna. Fish Physiol Biochem. 2016;42(2):787-794.

92. Choi YA, Kang SS, Jin EJ. BMP-2 treatment of C3H10T1/2 mesenchymal cells blocks MMP-9 activity during chondrocyte commitment. Cell Biol Int. 2009;33(8):887-892.

93. Ge X, Ma X, Meng J, Zhang C, Ma K, Zhou C. Role of Wnt-5A in interleukin-1beta-induced matrix metalloproteinase expression in rabbit temporomandibular joint condylar chondrocytes. Arthritis Rheum. 2009;60(9):2714-2722.

94. Rabelo Fde S, da Mota LM, Lima RA, et al. The Wnt signaling pathway and rheumatoid arthritis. Autoimmun Rev. 2010;9(4):207-210.

95. Luyten FP, Tylzanowski P, Lories RJ. Wnt signaling and osteoarthritis. Bone. 2009;44(4):522-527. 
96. Usami Y, Gunawardena AT, Iwamoto M, Enomoto-Iwamoto M. Wnt signaling in cartilage development and diseases: lessons from animal studies. Lab Invest. 2016;96(2):186-196.

97. Nakamura Y, Nawata M, Wakitani S. Expression profiles and functional analyses of Wnt-related genes in human joint disorders. Am J Pathol. 2005;167(1):97-105.

98. Imai K, Morikawa M, D’Armiento J, Matsumoto H, Komiya K, Okada Y. Differential expression of WNTs and FRPs in the synovium of rheumatoid arthritis and osteoarthritis. Biochem Biophys Res Commun. 2006;345(4):1615-1620.

99. Sen M, Lauterbach K, El-Gabalawy H, Firestein GS, Corr M, Carson DA. Expression and function of wingless and frizzled homologs in rheumatoid arthritis. Proc Natl Acad Sci USA. 2000;97(6):2791-2796.

100. Hiyama A, Sakai D, Risbud MV, et al. Enhancement of intervertebral disc cell senescence by WNT/beta-catenin signaling-induced matrix metalloproteinase expression. Arthritis Rheum. 2010;62(10): 3036-3047.

101. Ma B, van Blitterswijk CA, Karperien M. A Wnt/beta-catenin negative feedback loop inhibits interleukin-1-induced matrix metalloproteinase expression in human articular chondrocytes. Arthritis Rheum. 2012;64(8):2589-2600.

102. Papathanasiou I, Malizos KN, Tsezou A. Bone morphogenetic protein2-induced Wnt/beta-catenin signaling pathway activation through enhanced low-density-lipoprotein receptor-related protein 5 catabolic activity contributes to hypertrophy in osteoarthritic chondrocytes. Arthritis Res Ther. 2012;14(2):R82.

103. Chen M, Zhu M, Awad H, et al. Inhibition of beta-catenin signaling causes defects in postnatal cartilage development. J Cell Sci. 2008;121(Pt 9):1455-1465.

104. Nakashima A, Tamura M. Regulation of matrix metalloproteinase-13 and tissue inhibitor of matrix metalloproteinase-1 gene expression by WNT3A and bone morphogenetic protein-2 in osteoblastic differentiation. Front Biosci. 2006;11:1667-1678.

105. Tamamura Y, Otani T, Kanatani N, et al. Developmental regulation of Wnt/beta-catenin signals is required for growth plate assembly, cartilage integrity, and endochondral ossification. J Biol Chem. 2005;280(19):19185-19195.

106. Pufe T, Harde V, Petersen W, Goldring MB, Tillmann B, Mentlein R. Vascular endothelial growth factor (VEGF) induces matrix metalloproteinase expression in immortalized chondrocytes. J Pathol. 2004;202(3):367-374.
107. Mayr-Wohlfart U, Waltenberger J, Hausser H, et al. Vascular endothelial growth factor stimulates chemotactic migration of primary human osteoblasts. Bone. 2002;30(3):472-477.

108. Ortega N, Wang K, Ferrara N, Werb Z, Vu TH. Complementary interplay between matrix metalloproteinase-9, vascular endothelial growth factor and osteoclast function drives endochondral bone formation. Dis Model Mech. 2010;3(3-4):224-235.

109. Bergers G, Brekken R, McMahon G, et al. Matrix metalloproteinase-9 triggers the angiogenic switch during carcinogenesis. Nat Cell Biol. 2000;2(10):737-744.

110. Engsig MT, Chen QJ, Vu TH, et al. Matrix metalloproteinase 9 and vascular endothelial growth factor are essential for osteoclast recruitment into developing long bones. J Cell Biol. 2000;151(4): 879-889.

111. Bouwens EA, Stavenuiter F, Mosnier LO. Mechanisms of anticoagulant and cytoprotective actions of the protein C pathway. J Thromb Haemost. 2013;11(Suppl 1):242-253.

112. Weiler H. Regulation of inflammation by the protein $\mathrm{C}$ system. Crit Care Med. 2010;38(2 Suppl):S18-S25.

113. Griffin JH, Zlokovic BV, Mosnier LO. Protein C anticoagulant and cytoprotective pathways. Int J Hematol. 2012;95(4):333-345.

114. Griffin JH, Zlokovic BV, Mosnier LO. Activated protein C: biased for translation. Blood. 2015;125(19):2898-2907.

115. Shen K, Murphy CM, Chan B, et al. Activated protein C (APC) can increase bone anabolism via a protease-activated receptor (PAR) $1 / 2$ dependent mechanism. J orthopaed Res. 2014;32(12):1549-1556.

116. Nguyen M, Arkell J, Jackson CJ. Activated protein C directly activates human endothelial gelatinase A. J Biol Chem. 2000;275(13): 9095-9098.

117. Xue M, March L, Sambrook PN, Jackson CJ. Differential regulation of matrix metalloproteinase 2 and matrix metalloproteinase 9 by activated protein C: relevance to inflammation in rheumatoid arthritis. Arthritis Rheum. 2007;56(9):2864-2874.

118. Buisson-Legendre N, Smith S, March L, Jackson C. Elevation of activated protein $\mathrm{C}$ in synovial joints in rheumatoid arthritis and its correlation with matrix metalloproteinase 2. Arthritis Rheum. 2004; 50(7):2151-2156.

119. Xue M, McKelvey K, Shen K, et al. Endogenous MMP-9 and not MMP-2 promotes rheumatoid synovial fibroblast survival, inflammation and cartilage degradation. Rheumatology. 2014;53(12): $2270-2279$.
Metalloproteinases In Medicine

\section{Publish your work in this journal}

Metalloproteinases In Medicine is an international, peer reviewed, open access journal that aims to provide a platform for the discussion and dissemination of knowledge about the role that metalloproteinases - such as matrix metalloproteinases (MMP), ADAMs, ADAMTSs, and astacins, as well as their inhibitors - play in diseases.

\section{Dovepress}

The manuscript management system is completely online and includes a very quick and fair peer review system, which is all easy to use. Visit http://www.dovepress.com/testimonials.php to read real quotes from published authors. 